\title{
Coronary Artery Dissection and Perforation Complicating Percutaneous Coronary Intervention - A Review
}

\author{
Z Rahman, M Ullah, AK Choudhury \\ Department of Cardiology, NICVD, Dhaka.
}

\begin{abstract}
:
Keywords:

Percutaneous

After its introduction by Andrew R. Gruentzig in 1977 percutaneous coronary intervention (PCI) is widely utilized in the treatment of symptomatic coronary artery disease. Though it has numerous benefits, serious and potentially life-threatening complications of PCI can occur, including iatrogenic coronary artery dissection and perforation. The incidence of these complications has been augmented by the development of coronary interventional devices intended to remove or ablate tissue.

intervention

(PCI), Coronary

artery dissection.

Here we review the classification, incidence, pathogenesis, clinical sequelae and management of coronary artery dissection and perforation in the current era due to PCI. Specifically, the current angiographic classifications of coronary artery dissections and perforations are reviewed. The findings of several recent, registries of PCI-related coronary artery perforations and dissection are summarized. The management of coronary artery dissection and perforation is discussed in details, including the application of newer modalities such as covered stents.
\end{abstract}

(Cardiovasc. j. 2011; 3(2): 239-247)

\section{Introduction:}

Percutaneous coronary intervention (PCI) is the most popular and increasingly utilized in the treatment of coronary artery disease. PCI has numerous benefits. Serious and potentially lifethreatening complications of PCI can also occur, including iatrogenic coronary dissection and perforation. Up to $30 \%$ of all conventional balloon angioplasties result in angiographically significant coronary artery dissection. .12 In recent studies, perforation has been reported to occur in $0.3-0.6 \%$ of all patients undergoing PCI. $\frac{3-6}{}$ The incidence of these complications was high in Stenting with predilatation but subsequent studies show no differences between these two procedures. Perforations has been augmented by the development of coronary interventional devices intended to remove or ablate tissue, such as transluminal extraction coronary atherectomy, directional coronary atherectomy, excimer laser coronary angioplasty and high-speed mechanical rotational atherectomy. Here we review the incidence, causes, clinical sequelae and management of coronary artery dissection and perforation in the current era. ${ }^{7}$

\section{Coronary Artery Dissection:}

Percutaneous coronary intervention, which depends upon mechanical dilatation of the artery or ablation of atherosclerotic plaque, is requisitely associated with plaque fracture, intimal splitting and localized medial dissection - these tears may extend into the media for varying distances, and may even extend through the adventitia resulting in frank perforation.

\section{Incidence of coronary artery dissection:}

Up to $30 \%$ of all conventional balloon angioplasties result in angiographically significant coronary artery dissection. $\cdot \frac{8,9}{}$ But all dissections are not clinically significant.

\section{Type of dissection:}

The National Heart, Lung and Blood Institute (NHLBI) classification system for intimal tears, developed by the Coronary Angioplasty Registry, was put forth in the pre-stent era for the classification of dissection types after balloon angioplasty. Dissections in this scheme are graded based upon their angiographic appearances as types A through $\mathrm{F}^{12}$ (Figure 1). 
Type A dissections represent minor radiolucent areas within the coronary lumen during contrast injection with little or no persistence of contrast after the dye has cleared.

Type B dissections are parallel tracts or a double lumen separated by a radiolucent area during contrast injection, with minimal or no persistence after dye clearance.

Type $\mathrm{C}$ dissections appear as contrast outside the coronary lumen ("extraluminal cap") with persistence of contrast after dye has cleared from the lumen.

Type D dissections represent spiral ("barber shop pole") luminal filling defects, frequently with excessive contrast staining of the dissected false lumen.

Type E dissections appear as new, persistent filling defects within the coronary lumen.

Type $\mathrm{F}$ dissections represent those that lead to total occlusion of the coronary lumen without distal antegrade flow. In rare cases, a coronary artery dissection may propagate retrograde and involve the ascending aorta..$\underline{13}$



Fig.-1: National Heart, Lung and Blood Institute (NHLBI) classification system for coronary artery dissection types. Types $A$ and $B$ are generally clinically benign, whereas types $C$ through $F$ have clinically significant morbidity and mortality if untreated.

\section{Coronary Artery Perforation:}

Coronary perforation occurs when a dissection or intimal tear propagates outward sufficient to completely penetrate the arterial wall. A significant risk factor for perforation during PTCA is the balloon to artery ratio. In the report by Ajluni et al balloon perforations occurred from a measured balloon to artery ratio of $1.3 \pm 0.3$, which was significantly larger than the balloon to artery ratio of $1.0 \pm 0.3$ for other lesions in which perforation did not occur $(p<0.001){ }^{3}$

Similarly, in a registry by Ellis et al, the balloon to artery ratio of those patients undergoing PTCA complicated by perforation was $1.19 \pm 0.17$ versus $0.92 \pm 0.16$ for those without perforation $(p=0.03) . \underline{4}$ This observation has been confirmed in another large randomized study in which a balloon to artery ratio $>1.1$ was shown to result in a $2-3$ fold increase in severe dissection leading to abrupt closure compared to a balloon/artery ratio $<1.1 . \underline{14}$ In addition, balloon rupture, particularly those associated with pinhole leaks (as opposed to longitudinal tears), may create high pressure jets that increase the risk of dissection or perforation.(Figure2)

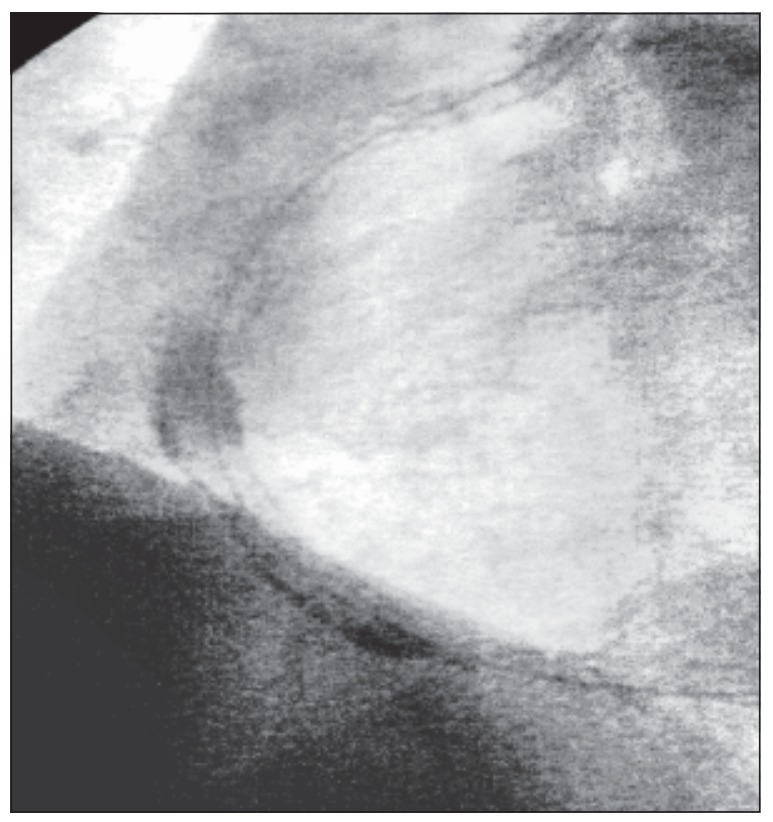

Fig.-2: Coronary artery dissection as a result of balloon perforation. (A) Initial cutting balloon inflation for treatment of diffuse in-stent restenosis of the right coronary artery. Examination of the cutting balloon ex vivo revealed a pinhole perforation. This dissection was treated with prolonged balloon inflation with complete sealing of the intimal entry site. 


\section{Incidence of coronary perforation:}

In agreement with previous reports with the use of non-debulking procedures, one study demonstrated that the incidence of coronary perforation was $0.1 \% .{ }^{15,16}$ Since new interventional methods are currently used to overcome the limitations of conventional PCI along with the adjunctive use of GP IIb/IIIa inhibitors, the risk of coronary perforation is reported to be much higher. ${ }^{17-20}$ The wide range of reported incidence of perforations may be attributable to different definitions of vessels perforations, the clinical spectrum of cases, the prevalence of chronic coronary occlusion interventions and the frequency of aggressive debulking use in each institution.

\section{Causes:}

The development of debulking devices which cut, vaporize, or drill the vessel wall, such as directional coronary atherectomy (DCA), excimer laser angioplasty and rotational or extraction atherectomy devices may be associated with the increase of perforations (0.5-3\%). ${ }^{21,22}$ Again, the use of devices intended to remove or ablate tissue were associated with higher perforation rates than PTCA alone. Two recent registries of cutting balloon angioplasty report a low incidence of perforation with this device. ${ }^{23,24}$

Additionally, the use of the recently developed hydrophilic and heavy-weight guidewires has increased the frequency of this complication. ${ }^{25}$ However, guidewire-related perforations can occur by the distal wire itself or by a fractured guidewire. The use of GP IIb/IIIa inhibitors confers no significantly increased risk of perforation or tamponade, once these complications occur but they are related to a higher risk of fatal bleeding. ${ }^{6}$

Risk increases with complex lesion morphology such as chronic total occlusions (especially long standing with bridging collaterals), angulated calcific lesions, tortuous vessels, bifurcation or ostial lesions and eccentric or long lesions (>10 $\mathrm{mm}$ ).

The characteristics of specific stents (i.e. stiff stents, requiring high pressure inflation for sufficient expansion) increase the risk of perforation considerably even though these stents is preferable in lesions where the possibility of restenosis is considered to be high. ${ }^{26}$ Specific PCI techniques such as kissing balloons and high pressure inflation increase the risk of perforation.

\section{Type of perforation:}

Ellis et al evaluated a novel angiographic classification scheme for coronary artery perforations as a predictor of outcome. ${ }^{14}$ In a multicenter registry of 12,900 PCIs, 62 (0.5\%) perforations were reported and categorized as:

Type I, extraluminal crater without extravasation; Type II, epicardial fat or myocardial blush without contrast jet extravasation;

Type III, extravasation through frank (> $1 \mathrm{~mm})$ perforation; or Type III "cavity spilling" (CS) referring to Type III perforations with contrast spilling directly into either the left ventricle, coronary sinus or other anatomic circulatory chamber. (Figures 3 and 4)

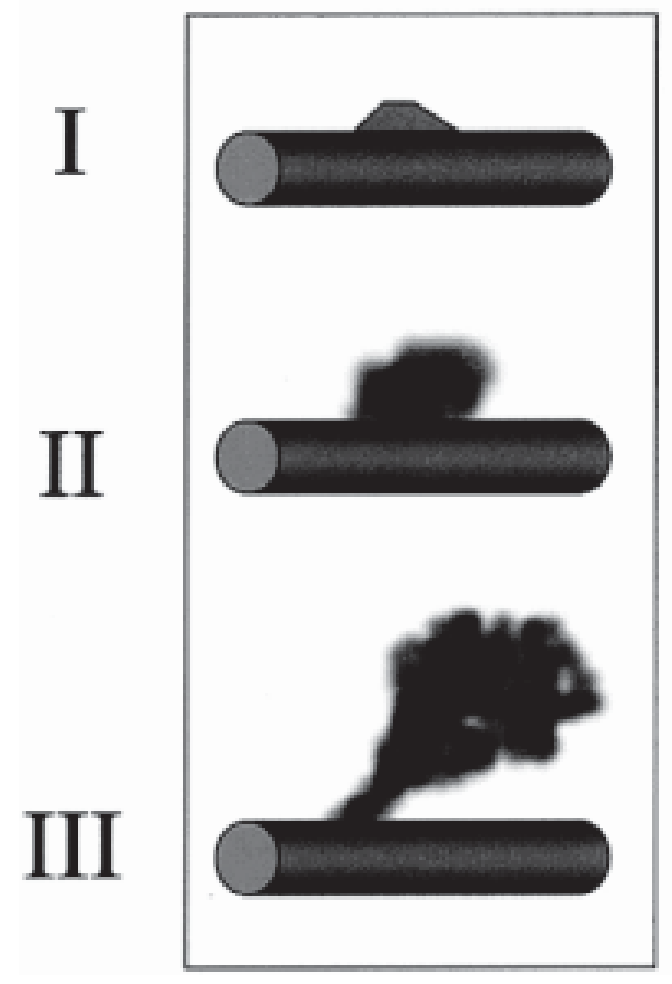

Fig.-3: Ellis classification scheme for coronary artery perforations. Types I and II are "contained" perforations, whereas Type III is a "free" perforation with continuous extravasation of contrast. A more benign Type III "cavity spilling" perforation is also described in which contrast spills directly into an anatomic circulatory chamber. 




Fig.-4: An Ellis Type III perforation of the left anterior descending coronary artery at the site of a major diagonal. Arrow denotes the perforation site, and "jet" of contrast streaming into pericardial space is defined by arrowheads. A perfusion balloon was placed and the patient taken for emergent coronary artery repair and bypass.

Interestingly, the Ellis Type I perforation is angiographically identical to the previously described NHBLI Type $\mathrm{C}$ dissection, reinforcing the notion that a continuum exists between dissection and perforation.

In another large retrospective analysis, Ajluni et al reviewed 8,932 PCIs in which coronary artery perforation was reported in $35(0.4 \%) .{ }^{3}$ Perforations were classified angiographically as a: 1) free perforation, defined as free contrast extravasation into the pericardium (Ellis Type III); or 2) contained perforation, defined as a contained extraluminal blush or localized rounded crater of contrast extending outside the contrast-filled vascular lumen (Ellis Type I or II).

\section{Clinical outcome after perforation:}

The frequency of adverse clinical outcomes relates to the severity of the coronary perforation. Perforations with cardiac tamponade are closely associated with mortality. ${ }^{27,28}$. In cases of coronary perforation, myocardial infarction rates occur in $16.7-50 \%$, emergency surgery in 50\% and death results in $9-19 \%$, despite more aggressive treatment. ${ }^{2728}$ Clinical follow up for more than a year after the procedure demonstrated that clinical events were relatively uncommon, including only one patient requiring surgery. Limited studies have reported the occurrence of late pseudoaneurym formation following coronary perforation most commonly after DCA and cutting balloon use. ${ }^{27}$

Concurrent with prior reports, Ajluni et al. found that overall clinical outcomes were worse for patients with free perforations (tamponade 20\%, CABG $60 \%$, death 20\%) than with contained perforations (tamponade $6 \%$, CABG $24 \%$, death $6 \%$ ).

The use of devices intended to remove or ablate tissue were associated with higher perforation rates than PTCA alone (1.3\% vs. $0.1 \%)$. Women and the elderly were also at increased relative risk. The investigators reported that Type I perforations were associated with no deaths or myocardial infarction, and tamponade in $8 \%$. Type II perforations, when treated with a prolonged balloon inflation, resulted in no deaths and a low incidence of adverse sequelae (myocardial infarction in 14\%, tamponade in 13\%). Type III perforations were associated with the rapid development of cardiac tamponade (63\%), the need for urgent bypass surgery (63\%) and a high mortality (19\%). Type III "cavity spilling" perforations, however, were associated with less catastrophic consequences (no deaths, myocardial infarction or tamponade resulted)

"Of 2991 conventional PCI procedures performed in our department, there were only 5 cases of coronary perforation ( $0.1 \%)$. Guidewire perforations constituted $20 \%$ of all perforations and $80 \%$ were caused during or after stent implantation. It is important to note that most cases (80\%) were managed with prolonged balloon occlusion. Haemopericardium occurred in $60 \%$ of patients with coronary perforation and pericardial drainage was performed in 2 cases because of haemodynamic instability. There was one procedural-related death in these series. ${ }^{29}$

\section{Spontaneous coronary artery dissection:}

Spontaneous coronary artery dissection (SCAD) is a rare condition that usually occurs in relatively young patients who are predominantly female. Seldom could it be a cause of acute myocardial ischemia leading to a sudden cardiac death. SCAD 
consists of intramural hematoma formation or, rarely, intimal tears that initiate and propagate the dissection in the vessel wall. In rare cases, the SCAD occurs in male patients. Many strategies could be considered in patients with SCAD, such as PCI, bypass surgery, or conservative medical management. In general, the long-term prognosis of patients with SCAD is considered favorable if they survive the acute phase. ${ }^{30}$

\section{Risk factors for spontaneous coronary artery dissection:}

The most frequent were pregnancy or postpartum state, coronary artery disease, and exercise. Less common risk factors included Marfan's syndrome, hypersensitivity vasculitis, Kawasaki's disease $\underline{31}$ and alpha-1-antitrypsin deficiency $\underline{32}$ oral contraceptives, and hypertension. ${ }^{33}$

Coronary artery perforation has been reported to be more frequent in elderly female patients, probably due to their small vasculature. ${ }^{4}$

The incidence of spontaneous coronary dissection occurs at rates of $0.1-0.28 \%$ of all angiographic studies. $\stackrel{34}{ }$ Blunt trauma, $\underline{35}$ cocaine use ${ }^{36}$ and extension of aortic dissection $\underline{37}$ have also been reported to result in coronary dissection.

In general, spontaneous coronary dissection is a life-threatening condition; however, in those surviving the initial event, the survival rate is reported to be $78 \%-82 \% .38,39$

Coronary Artery Dissection Complicating Radiofrequency Catheter Ablation via the Retrograde approach. ${ }^{40}$

\section{Diagnosis:}

Coronary perforation can be easily diagnosed by coronary angiography and echocardiography and it is usually accompanied by new episodes of chest pain, haemodynamic deterioration and electrocardiographic changes. ${ }^{3,41}$

Angiographic evidences of perforation are the presence of blush, jet, coronary sinus compression and contrast in pericardium. ${ }^{3,4}$ The most difficult type of diagnosis is when there is extramural blood collection on the vessel wall, which can only be detected indirectly from coronary angiography. Of interest, there is no angiographic evidence of perforation in 10 to $20 \%$. Delayed tamponade can occur several hours to several days after angioplasty and is common in perforations induced by guidewire or GP IIb/IIIa. ${ }^{42}$ Thus this diagnosis should remain high on the list of the differential diagnosis of post-PCI hypotension.

MRI can demonstrate acute myocardial infarction due to posttraumatic coronary artery dissection. ${ }^{43}$

\section{Prevention and management of coronary perforation:}

Since the occurrence of perforation is highly associated with the selection of an appropriate device for the lesion, the morphologic assessment of the lesions by intravascular ultrasound (IVUS) would be very helpful. IVUS can provide not only the location of calcification but also the severity, the depth and the eccentricity of calcification, which are thought to influence the risk of perforation. ${ }^{44}$

Meticulous attention to guidewire position, to device sizing and to the 'blind high pressure technique' is required since they are all highly related to the risk of coronary perforation. ${ }^{45}$ Another cause of cardiac perforation occurs as a consequence of the use of a temporary pacing wire, of which interventional cardiologists should always be aware. ${ }^{46}$ So careful manipulation of pacing wire can prevent these devastating complications. Early management is crucial for plugging the perforation without resorting to surgery. If the perforation site is visible, the blood flow of the perforated branch should be blocked immediately by the plain balloon, which was used for the procedure. Balloon inflation should be performed at the lowest possible pressure to promote haemostasis, generally less than $2 \mathrm{~atm}$ and should last for 5 to $15 \mathrm{~min}$. If myocardial ischaemia develops, this should be exchanged by a perfusion balloon, which enables the blood to perfuse to the distal portion of the vessel. Prolong balloon inflation may avoid surgery in $60-70 \%$ of the cases. ${ }^{46}$ In the present series, prolonged balloon inflations were used in $80 \%$ of patients and they were successful in sealing the coronary perforations in all but 1 patient. (Figure 5 and 6)

In the meantime, if cardiac tamponade and low blood pressure ensue, pericardiocentisis should be performed immediately ${ }^{47}$. In a study, a case of delayed pericardial haemorrhage occurred in a patient of perforation type I, which did not require pericardiocentisis. Two out of three cases of 
patients with perforation type III developed cardiac tamponade, of which one required pericardiocentisis. Administration of fluids could prevent cardiac tamponade and hypovolemic shock.

For haemostasis, protamine should be administered to negate the effects of heparin and in a dosage to achieve a partial thromboplastin time of less than 60 seconds or an ACT of less than 150 second. ${ }^{48,49}$ The administration of protamine seems to be safe with no vessel thrombosis complications. Platelet transfusion is useful in patients treated with abciximab, but not with tirofiban or eptifibatide ${ }^{50}$

Delivery of covered stents (autologous vein cover or polytetrafluoroethylene (PTFE) covered stents) may be attempted as an optional treatment before resorting to emergency surgery, especially for perforation sites located in the proximal or midportion of the index vessel. ${ }^{51-53}$ However, preparing these stents is technically difficult, time-consuming and the restenosis rates of these devices are known to be high.

If a large perforation is causing serious ischaemia, the guidewire cannot be re-crossed or the bleeding continuous, emergency surgery is the only option. Coronary perforation accounts for $20 \%$ of referrals for urgent surgery. ${ }^{54}$ If the situation allows, this should be done with a perfusion balloon in place and dilated at low pressure.

Embolization of gel foam or thrombogenic metallic (stainless steel/platinum) coils into the leaking vessels is another treatment option when perforation persists. ${ }^{55}$ If the perforation is too distal, or in a small vessel or it is near to a chronic total occlusion or surgery is not possible, there is always the possibility of coil embolization onto the site through an infusion catheter. However, this technique is complicated, requiring a special delivery system and adds to the cost of the procedure.

Treatment options for SCAD have increased significantly, roughly paralleling the development of coronary angiography. These include medical therapy, percutaneous intervention, and coronary bypass. It is not possible to define the optimal treatment from in our review. Of all the treatment options, no one option stands out as superior to the others. Our observations suggest that no matter what treatment is chosen, more than 95\% of patients are likely to survive if the patient survives to the time of diagnosis.

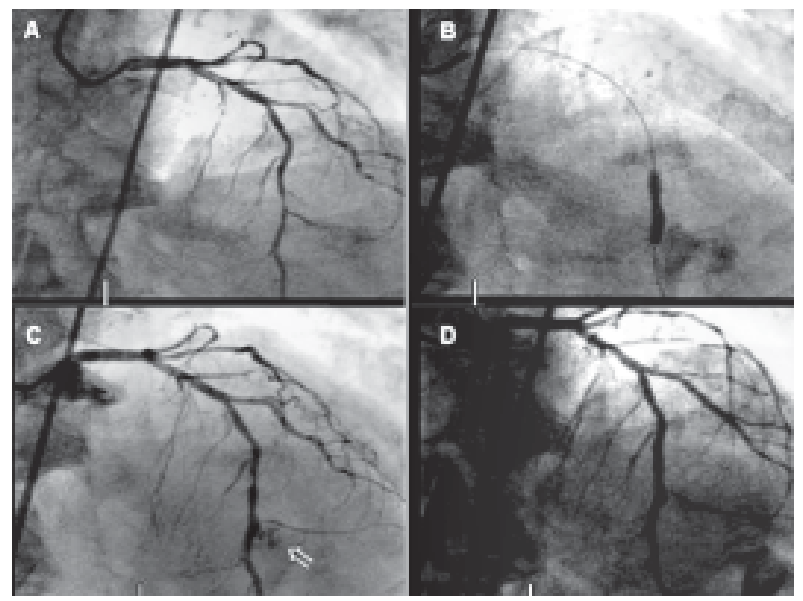

Fig.-5: Type II perforation. (A) A calcified lesion of the mid-LAD (B) A conventional balloon angioplasty was performed. (C) After several balloon inflations, epicardial staining by contrast extravasation occurred. (D) Extravasation was terminated after prolonged balloon inflation.

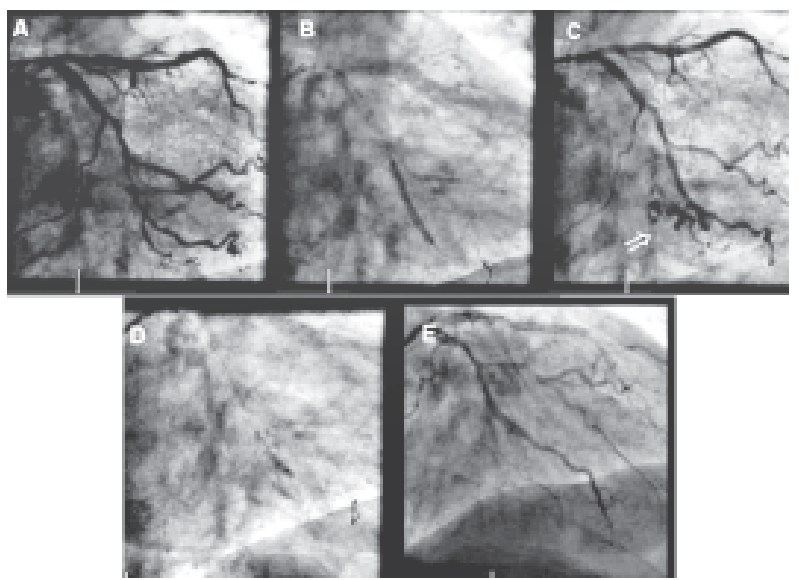

Fig.-6: Type III perforation. (A) A calcified lesion of the mid-LCX. (B) A conventional balloon angioplasty was performed. (C) After several balloon inflations, epicardial staining by contrast extravasation occurred. (D) A long inflation of the balloon at a very low pressure was performed. (E) Extravasation was terminated after prolonged balloon inflation.

\section{Clinical outcome after perforation:}

The frequency of adverse clinical outcomes relates to the severity of the coronary perforation. Perforations with cardiac tamponade are closely associated with mortality. ${ }^{56,57}$ In cases of coronary perforation, despite more aggressive treatment, 
myocardial infarction rates occur in $16.7-50 \%$, emergency surgery in 50\% and death results in 9 $19 \%{ }^{56,57}$ Clinical follow up for more than a year after the procedure demonstrated that clinical events were relatively uncommon, including only one patient requiring surgery. Limited studies have reported the occurrence of late pseudoaneurysm formation following coronary perforation most commonly after DCA and cutting balloon use. ${ }^{57}$

\section{Conclusion:}

Coronary artery dissections and perforations remain common complications during PCI but clinical sequelae have been minimized by early diagnosis and routine use of coronary stents. Perforation, although rare, can often be a lifethreatening complication. Coronary perforation remains a dreadful complication but with low incidence in the current interventional era. Prevention is the best treatment of this complication. ${ }^{58}$

Early and spot recognition and attention to the angiographic appearance of the perforation is essential for the successful management of this complication. Those perforations which are "contained" angiographically carry a more benign prognosis than those which are freely extravagating contrast into the pericardium. Treatment should be aimed at sealing the perforation with low pressure prolonged conventional or perfusion balloon inflation, prudent reversal of anticoagulation and use of covered stents. Echocardiography should be performed in all cases of coronary perforation and urgent pericardiocentesis if tamponade develops. In cases where sealing of the perforation by conservative measures cannot be achieved, emergency bypass surgery must be performed. ${ }^{59}$

\section{References:}

1. Ellis SG, Ajluni S, Arnold AZ. Increased coronary perforation in the new device era. Incidence, classification, management, and outcome. Circulation 1994;90:2725-2730.

2. Dippel EJ, Kereiakes DJ, Tramuta DA. Coronary perforation during percutaneous coronary intervention in the era of abciximab platelet glycoprotein IIb/IIIa blockade: an algorithm for percutaneous management. Cathet Cardiovasc Intervent 2001;52(3):279-86.

3. Coronary Artery angiographic changes after PTCA: Manual of Operations NHBLI PTCA Registry 1985-6:9.
4. Goldstein JA, Casserly IP, Katsiyiannis WT. Aortocoronary Dissection Complicating a Percutaneous Coronary Intervention. J Invas Cardiol 2003;15:89-92.

5. Ellis SG, Vandormael MG, Cowley MJ. Coronary morphologic and clinical determinants of procedural outcome with angioplasty for multivessel coronary disease. Implications for patient selection. Multivessel Angioplasty Prognosis Study Group. Circulation 1990; 82(4):1193-1202.

6. Kimbiris, D., Iskandrian, AS, Goel, I., Bemis, CE, Gehl, L. Owens, J. Transluminal coronary angioplasty complicated by coronary perforation. Cathet Cardiovasc Diagn 1982; 8 , pp. 481-487.

7. Saffitz, JE, Rose, TE, Oaks, JB and Roberts, WC. Coronary arterial rupture during coronary angioplasty. Am J Cardio 1983. 51 : 902-904.

8. Witzke, CF, Martin-Herrero, F., Clarke, SC, Pomerantzev, E. and Palacios, IF. The changing pattern of coronary perforation during percutaneous coronary intervention in the new device era. Invasive Cardiol 200416 : 257-301.

9. Ramana, RK, Arab, D., Joyal, D., Steen, L., Cho, L. Lewis, B. Coronary artery perforation during percutaneous coronary intervention: incidence and outcomes in the new interventional era. J Invasive Cardiol 2005; 17: 603-605.

10. Fasseas, P., Orford, JL, Panetta, CJ, Bell, MR, Denktas, AE Lennon, RJ et al. Incidence, correlates, management, and clinical outcome of coronary perforation: analysis of 16,298 procedures. Am Heart $J$ 2004; 147: 140-145.

11. Rogers, JH and Lasala, JM. Coronary artery dissection and perforation complicating percutaneous coronary intervention. J Invasive Cardiol. 2004;16 : 493-499.

12. Bittl, JA, Ryan Jr, TJ, Keaney Jr, JF, Tcheng, JE, Ellis, SG Isner, JM. Coronary artery perforation during excimer laser coronary angioplasty. The percutaneous excimer laser coronary angioplasty registry. J Am Coll Cardiol.1993;21 : 1158-1165.

13. Holmes Jr, DR, Reeder, GS, Ghazzal, ZM, Bresnahan, JF, King, SB 3rd Leon, MB. Coronary perforation after excimer laser coronary angioplasty: the excimer laser coronary angioplasty registry experience. $\mathrm{J} \mathrm{Am} \mathrm{Coll}$ Cardiol. 1994; 23 : 330-335.

14. Orford JL, Fasseas P, Denktas AE. Safety and efficacy of cutting balloon angioplasty: the Mayo Clinic experience. J Invas Cardiol 2002; 14(12):720-4.

15. Kondo T, Kawaguchi K, Awaji Y \& Mochizuki M. Immediate and chronic results of cutting balloon angioplasty: a matched comparison with conventional angioplasty. Clinical Cardiol 1997; 20(5):459-63.

16. Kahler, J., Koster, R., Brockhoff, C., Reimers, J., Baldus, S. Terres, W. Initial experience with a hydrophilic-coated guidewire for recanalization of chronic coronary occlusions. Catheter Cardiovasc Interv 2000; $49: 45-50$. 
17. Shirakabe, A., Takano, H., Nakamura, S., Kikuchi, A., Sasaki, A. Yamamoto, E. Coronary perforation during percutaneous coronary intervention. Int Heart J $2007 ; 48: 1-9$

18. Fukutomi, T., Suzuki, T., Popma, JJ, Hosokawa, H., Yokoya, K. Inada, T. Early and late clinical outcomes following coronary perforation in patients undergoing percutaneous coronary intervention. Circ J 2002;66 : 349-356.

19. Javaid, A., Buch, AN, Satler, LF, Kent, KM, Suddath, WO Lindsay Jr, J. Management and outcomes of coronary artery perforation during percutaneous coronary intervention. Am J Cardiol 2006;98: 911-914.

20. Panagiota Georgiadou, George Karavolias, Eftihia Sbarouni, Stamatis Adamopoulos, John Malakos, Vassilis Voudris. Coronary artery perforation in patients undergoing percutaneous coronary intervention: a single-centre report. Acute Cardiac Care 2009(Dec); 11(4):216 - 221 .

21. Capuano C, Sesana M, Predolini S, Leonzi O, Cuccia C. Case report: a very large dissection in the left anterior descending coronary artery of a 56-year-old man. Cardiovasc Revasc Med 2006(Oct-Dec);7(4):240-2.

22. Borczuk AC, van Hoeven KH \& Factor SM. Review and hypothesis: the eosinophil and peripartum heart disease (myocarditis and coronary artery dissection)coincidence or pathogenetic significance. Cardiovasc Res 1997;33(3):527-32.

23. Davila FM, Portela MD, Rojo MG. Coronary artery dissection in alpha-1-antitrypsin deficiency. Histopathology 1999; 34(4):376-378.

24. Ellen A. Thompson; SueEllen Ferraris; Todd Gress; Victor Ferraris. Gender Differences and Predictors of Mortality in Spontaneous Coronary Artery Dissection: A Review of Reported Cases. J Invasive Cardiol 2005; 17(1):59-61.

25. Nishikawa H, Nakanishi S, Nishiyama S, et al. Primary coronary artery dissection observed at coronary angiography. Am J Cardiol 1988; 61:645-648.

26. Masuda T, Akiyama H, Kurosawa T \& Ohwada T. Longterm follow-up of coronary artery dissection due to blunt chest trauma with spontaneous healing in a young woman. Intensive Care Med 1996;22(5):450-2.

27. Steinhauer JR \& Caulfield JB. Spontaneous coronary artery dissection associated with cocaine use: a case report and brief review. Cardiovasc Pathol 2001; 10(3):141-5.

28. Virmani R, Forman MB, Robinowitz M \& McAllister HA Jr. Coronary artery dissections. Cardiol Clin 1984; 2(4):633-46.

29. DeMaio SJ, Kinsella SH \& Silverman ME. Clinical Course and Long-Term Prognosis of Spontaneous Coronary Dissection. Am J Cardiol 1989;64:471-474.

30. Tsimikas S, Giordano FJ, Tarazi RY Spontaneous Coronary Dissection in Patients with Renal Transplantation. J Invas Cardiol 1999;11:316-21.
31. Louis F. Janeira From the St. Mary's Medical Center, Section of Electrophysiology, Evansville, IN JANEIRA, L.F. Coronary Artery Dissection Complicating Radiofrequency Catheter Ablation via the Retrograde Approach. A case of acute coronary dissection complicating a left-sided catbeter ablation procedure via the retrograde approacb. Pace 1998; 21:1327-1328.

32. Gunning, MG, Williams, IL, Jewitt, DE, Shah, AM, Wainwright, RJ and Thomas, MR. Coronary artery perforation during percutaneous intervention: incidence and outcome. Heart 2002; 88 : 495-498.

33. von Sohsten, R., Kopistansky, C., Marc Cohen, RN and Kussmaul, WG. Cardiac Tamponade in the 'New Device' Era: Evaluation of 6999 Consecutive Percutaneous Coronary Interventions. Am Heart $J$ 2000;140: 279-283.

34. Savas M. Tepe, James F. Glockner \& Paul Julsrud"'The International Journal of Cardiovascular Imaging 2006; 22: $97-100$

35. Hodgson, JM, Reddy, KG, Suneja, R., Nair, RN, Lesnefsky, EJ and Sheehan, HM Intracoronary ultrasound imaging: Correlation of plaque morphology with angiography, clinical syndrome and procedural results in patients undergoing coronary angioplasty. $J$ Am Coll Cardiol 1993;21: 35-44.

36. Colombo, A. and Stankovic, GCoronary perforations: Old screenplay, new actors!. J Invasive Cardiol 2004; 16: 302-303.

37. Witzke, CF, Martin-Herrero, F., Clarke, SC, Pomerantzev, E. and Palacios, IF. The changing pattern of coronary perforation during percutaneous coronary intervention in the new device era. Invasive Cardiol 2004; 16: 257-301.

38. von Sohsten, R., Kopistansky, C., Marc Cohen, RN and Kussmaul, WG. Cardiac Tamponade in the 'New Device' Era: Evaluation of 6999 Consecutive Percutaneous Coronary Interventions. Am Heart $J$ 2000;140: 279-283.

39. Rogers, JH and Lasala, JM. Coronary artery dissection and perforation complicating percutaneous coronary intervention. J Invasive Cardiol 2004; 16:493-499.

40. Briguori, C., Di Mario, C, De Gregorio, J., Sheiban, I., Vaghetti, M. and Colombo, A. Administration of protamine after coronary stent deployment. Am Heart J 1999;138:64-68.

41. Gunning, MG, Williams, IL, Jewitt, DE, Shah, AM, Wainwright, RJ and Thomas, MR. Coronary artery perforation during percutaneous intervention: incidence and outcome. Hear 2002;88:495-498.

42. Briguori, C., Nishida, T., Anzuini, A., Di Mario, C, Grube, E. and Colombo, AEmergency polytetrafluoroethylene-covered stent implantation to treat coronary ruptures. Circulation 2000; 102: 30283031. 
43. Caputo, R., Amin, N., Marvasti, M., Wagner, S., Levy, C. and Giambartolomei, A. Successful treatment of a saphenous vein graft perforation with an autologous vein-covered stent. Cathet Cardiovasc Intervent 1999;48:382-386.

44. Pienvichit, P. and Waters, J. Successful closure of coronary artery perforation using makeshift stent sandwich. Cathet Cardiovasc Intervent 2001; 54:209213.

45. Eshadri, N., Whitlow, PL, Acharya, N., Houghtaling, P., Blackstone, EH and Ellis, SG. Emergency coronary artery bypass surgery in the contemporary percutaneous coronary intervention era. Circulation 2002; 106: 2346-2350.

46. Assali, AR, Moustapha, A., Sdringola, S., Rihner, M. and Smalling, RW. Successful treatment of coronary artery perforation in an abciximab-treated patient by microcoil embolization. Catheter Cardiovasc Interv 2000; 51:487-489.
47. Fukutomi, T., Suzuki, T., Popma, JJ, Hosokawa, H., Yokoya, K. Inada, T. Early and late clinical outcomes following coronary perforation in patients undergoing percutaneous coronary intervention. Circ J 2002;66 :349-356.

48. Javaid, A., Buch, AN, Satler, LF, Kent, KM, Suddath, WO Lindsay Jr, J. Management and outcomes of coronary artery perforation during percutaneous coronary intervention. Am J Cardiol 2006; 98: 911914.

49. Panagiota Georgiadou, George Karavolias, Eftihia Sbarouni, Stamatis Adamopoulos, John Malakos, Vassilis Voudris. Coronary artery perforation in patients undergoing percutaneous coronary intervention: a single-centre report. Acute Cardiac Care 2009; 11(4): $216-221$.

50. Jason H. Rogers, John M. Lasala. Coronary Artery Dissection and Perforation Complicating Percutaneous Coronary Intervention. J Invasive Cardiol 2004; 16(9). 